\title{
Acolhimento e vínculo na humanização do cuidado de enfermagem às pessoas com diabetes mellitus
}

User embracement and attachment in the humanization of nursing care for people with diabetes mellitus Acogimiento y vínculo en la humanización del cuidado de enfermería a personas con diabetes mellitus

\author{
Cecilia Arruda', Denise Maria Guerreiro Vieira da Silva" \\ ' Universidade Federal de Santa Catarina, Hospital Universitário Polydoro Hernani de São Thiago, Núcleo de Estudos e \\ Assistência em Enfermagem e Saúde a Pessoas em Condição Crônica (Membro). Florianópolis-SC, Brasil. \\ "Universidade Federal de Santa Catarina, Departamento de Enfermagem, Programa de Pós-Graduação em Enfermagem, \\ Núcleo de Estudos e Assistência em Enfermagem e Saúde a Pessoas em Condição Crônica (Coordenadora). \\ Florianópolis-SC, Brasil.
}

Submissão: 10-04-2011 Aprovação: 08-11-2012

\section{RESUMO}

Pesquisa qualitativa que objetivou avaliar o acolhimento e o vínculo na prática da humanização dos cuidados de enfermagem às pessoas com Diabetes Mellitus em um serviço ambulatorial público. O suporte teórico foi a Política Nacional da Humanização do Ministério da Saúde/Brasil. A coleta de dados ocorreu em entrevistas semiestruturadas realizadas com vinte pessoas com diabetes tipo 1 ou tipo 2, entre março e maio de 2010. A análise resultou em quatro categorias que exploram a escuta e o diálogo, o relacionamento, a resolutividade e o acesso aos serviços de saúde. As pessoas com diabetes reconhecem o acolhimento e o vínculo como partes da atenção humanizada recebida, que se destaca pela valorização da dimensão subjetiva dos usuários.

Descritores: Acolhimento; Humanização da Assistência; Enfermagem; Diabetes Mellitus.

\begin{abstract}
It is a qualitative research, which aimed to evaluate the user embracement and attachment in the humanization of nursing care for people with Diabetes Mellitus in a public specialized outpatient service. The theoretical support was the National Policy of Humanization of the Health Ministry / Brazil. Data was collected through semi-structured interviews with twenty people with type 1 or type 2 diabetes, between 2010 March and May. The analysis resulted in four categories that explore listening and dialogue, relationships, problem solving and access. People with diabetes recognize the user embracement and attachment as part of humanized attention given, which is highlighted by the appreciation of the patients' subjective dimension.
\end{abstract}

Key words: User Embracement; Humanization of Assistance; Nursing; Diabetes Mellitus.

\section{RESUMEN}

Investigación cualitativa que objetivó evaluar el acogimiento y el vínculo en los cuidados de enfermería a las personas con diabetes mellitus en un servicio ambulatorio público. El soporte teórico fue la Política Nacional de Humanización del Ministerio de Salud/Brasil. La recolección de los datos empleó entrevistas semi estructuradas realizadas con veinte personas con diabetes tipo 1 o tipo 2, entre marzo y mayo de 2010. El análisis resultó en cuatro categorías que exploran: escucha y diálogo, relación, resolución y acceso. Las personas con diabetes reconocen el acogimiento y el vínculo como partes de la atención humanizada recibida, la cual se destaca por la valorización de la dimensión subjetiva de los usuarios.

Palabras clave: Acogimiento; Humanización de la Atención; Enfermería; Diabetes Mellitus.

Extraído da dissertação intitulada "Avaliação da Humanização do Cuidado de Enfermagem às Pessoas com Diabetes Mellitus", apresentada, em 2011, à Universidade Federal de Santa Catarina, Programa de Pós-Graduação em Enfermagem. Florianópolis-SC, Brasil.

\section{AUTOR CORRESPONDENTE Cecilia Arruda E-mail: cecillia_arruda@hotmail.com}




\section{INTRODUÇÃO}

O Diabetes Mellitus (DM) apresenta-se como um tema relevante por estar entre os maiores problemas de saúde pública, afetando em torno de 246 milhões de pessoas em todo o mundo. Até 2025, a previsão é de que esse número chegue a 380 milhões $^{(1)}$. A sociedade brasileira faz parte dessa alarmante realidade. Em 2006, contávamos com cerca de seis milhões de portadores, e as estimativas indicavam o alcance de dez milhões de pessoas em $2010^{(2)}$.

Para fazer frente a esta situação, as políticas em saúde no Brasil vêm dando cada vez maior atenção às pessoas com DM, especialmente a legislação mais atual. Como exemplo, podemos citar o provimento gratuito de medicamentos e equipamentos para aplicação de insulina e automonitoramento da glicemia capilar de portadores de DM inscritos em programas de educação para pessoas com DM e o SISHIPERDIA - programa informatizado de âmbito nacional para o cadastro e acompanhamento das pessoas com $\mathrm{DM}^{(3-4)}$.

Aliado a estes programas específicos, o sistema de saúde brasileiro propõe de maneira global, a assistência integral e humanizada, voltada não somente para o controle das doenças, mas também para a promoção da saúde e da cidadania das pessoas. Contudo, pouco sabemos a respeito de quanto ou de como esses avanços na legislação e nas políticas públicas vêm se efetivando na prática de modo a desenvolver a atenção em saúde de qualidade, que considere a pessoa em sua integralidade e em contextos específicos.

A realidade mostra-nos números desfavoráveis. São quatro milhões de mortes por ano relativas ao DM e suas complicações. Ocorre grande impacto econômico nos serviços de saúde como consequência dos custos para tratamento da doença e suas complicações, como doença cardiovascular, diálise por insuficiência renal crônica e cirurgias para amputação de membros inferiores. No Brasil, o DM associado à hipertensão arterial sistêmica representa $62,1 \%$ dos diagnósticos primários em pessoas com insuficiência renal crônica submetidas a diálise ${ }^{(1)}$. Ocorre também considerável impacto social com a redução da expectativa e da qualidade de vida dessas pessoas.

Estudos realizados em diferentes locais evidenciam o baixo controle glicêmico. Numa amostra com quase 600 pessoas com DM, a maioria encontrava-se fora dos alvos desejados de controle glicêmico e apenas $22 \%$ atingiram níveis de $\mathrm{HbA} 1 \mathrm{c}$ abaixo de $7,0 \%$, gerando elevada prevalência de complicações crônicas vasculares ${ }^{(5)}$. A adesão do paciente com DM ao tratamento medicamentoso encontra-se abaixo do recomendado pela literatura, evidenciando mau controle glicêmico ${ }^{(6)}$. Apesar de possuirmos recomendações, protocolos e diretrizes bem estabelecidas quanto ao manejo do DM, ainda há muito a avançar no atendimento à saúde de pessoas com esta condição crônica.

Algumas reflexões sobre estas circunstâncias e sobre como a enfermagem vem contribuindo para modificar essa situação na prática cotidiana dos serviços de saúde suscitaram-nos o interesse em realizar um estudo que mostrasse um retrato dessa realidade em um serviço especializado de atenção às pessoas com DM. O estudo avaliativo qualitativo foi a opção, focalizando dois conceitos que consideramos relevantes na atenção à saúde, como parte de um olhar para além do controle clínico da doença: acolhimento e vínculo. Esses dois conceitos integram a Política Nacional de Humanização.

Embora autores digam que a avaliação consiste fundamentalmente em fazer um julgamento de valor a respeito de uma intervenção ou sobre qualquer um de seus componentes, manifestar-se em relação a alguma coisa com o objetivo de ajudar na tomada de decisões ${ }^{(7)}$, a pesquisa avaliativa nos programas e serviços de saúde objetiva também a progressão do conhecimento conceitual em relação ao desenvolvimento do contexto de saúde em análise ${ }^{(8)}$.

No campo da saúde, a humanização diz respeito à atitude de usuários, gestores e trabalhadores de saúde comprometidos e corresponsáveis, acarretando um processo criativo e sensível de produção da saúde e de subjetividades. Refere-se ainda à organização social e institucional das práticas de atenção e gestão na rede do SUS.

O compromisso ético, estético e político da humanização assenta-se nos valores de autonomia e protagonismo dos sujeitos, de corresponsabilidade entre eles, de solidariedade nos vínculos estabelecidos, dos direitos dos usuários e da participação coletiva no processo de gestão ${ }^{(9)}$. Parece-nos que essa é a base sobre a qual toda atenção realizada pela enfermagem deve estar assentada.

A humanização dos serviços de saúde implica transformar o próprio modo como se concebe o usuário do serviço, de objeto passivo a sujeito; de necessitado de atos de caridade àquele que exerce o direito de ser usuário de um serviço que garanta ações técnica, política e eticamente seguras, prestadas por trabalhadores responsáveis. O enfoque à saúde apresenta-se numa dimensão ampliada, relacionada às condições de vida inseridas em um contexto sociopolítico e econômico ${ }^{(10)}$.

O acolhimento é um processo constitutivo das práticas de produção e promoção de saúde que implica responsabilização do profissional pelo usuário, ouvindo sua queixa, considerando suas preocupações e angústias, fazendo uso de uma escuta qualificada que possibilite analisar a demanda e, colocando os limites necessários, garantir atenção integral, resolutiva e responsável por meio da articulação das redes internas dos serviços e redes externas com outros serviços de saúde para a continuidade da assistência, quando necessário ${ }^{(9)}$.

A aproximação entre usuário e profissional de saúde promove um encontro, "ficar em frente um do outro", um e outro sendo sujeitos dotados de intenções, interpretações, necessidades, razões e sentimentos, mas em situação de desequilíbrio, de expectativas diferentes, em que um, o usuário, busca assistência em estado físico e emocional fragilizado, junto ao outro, um profissional que deve estar capacitado para atender e cuidar da causa de sua fragilidade. Desse modo, cria-se um vínculo, isto é, processo que ata ou liga, gerando uma ligação afetiva e ética entre ambos, numa convivência de ajuda e respeito mútuos $^{(9)}$.

Tanto o acolhimento quanto o vínculo são processos que se retroalimentam nas práticas de atenção à saúde, fomentando o cuidado humanizado. $\mathrm{O}$ acolhimento caracteriza-se especialmente pela escuta sensível, que considera as preocupações 
do usuário dos serviços de saúde em qualquer situação - tanto na chegada ao serviço de saúde quanto ao longo do seu acompanhamento pelos profissionais. O vínculo, por sua vez, expressa-se na atenção humanizada, com compartilhamento de saberes, na convivência, na ajuda e no respeito recíprocos entre profissional e usuário.

Dessa forma, este estudo teve como objetivo avaliar o vínculo e o acolhimento na prática da humanização dos cuidados de enfermagem a pessoas com diabetes mellitus, sob a perspectiva dos usuários de um serviço de atenção especializada em nível ambulatorial vinculado a um hospital geral de ensino público do Sul do Brasil, tendo como referência a Política Nacional de Humanização do Ministério da Saúde/Brasil.

\section{MÉTODO}

Trata-se de uma pesquisa avaliativa qualitativa, desenvolvida no ambulatório de um hospital geral público de médio porte localizado no Sul do Brasil. A escolha do local relaciona-se ao fato deste atender uma elevada demanda de pessoas com DM, que provêm de diversos municípios do Estado. A instituição hospitalar tem como proposta a filosofia do atendimento humanizado e possui formalizada a Comissão de Humanização e um Grupo de Trabalho Humanizado (GTH) que trabalha sob um regimento interno em prol de ações humanizadoras voltadas para o usuário do sistema de saúde e aos profissionais. O serviço tem amplo reconhecimento na área acadêmica pela qualidade da atenção que desenvolve, integrado por profissionais com vasta experiência e formação na área. Esses aspectos foram decisivos na escolha, uma vez que permitiriam mostrar uma realidade que, a princípio, atenderia o que está proposto na política de saúde.

A área ambulatorial de atenção a pessoas com DM foi constituída há 30 anos, logo no início da fundação da instituição. Atualmente, conta com uma equipe multiprofissional integrada por enfermeiros, médicos, nutricionistas, psicólogos e terapeutas ocupacionais. Mantém alto fluxo diário de assistência a usuários, que dispõem de consultas especializadas, serviços de educação em saúde, exames e acompanhamento em saúde. A equipe de enfermagem é composta por duas enfermeiras e uma técnica de enfermagem que prestam cuidados diversos aos usuários do ambulatório, participam da equipe de saúde multidisciplinar e coordenam a dinâmica de funcionamento do ambulatório.

O ambulatório abrange a atenção em saúde no nível de média complexidade, denominado na prática como "atenção especializada". No entanto, esta condição é recente, pois a instituição hospitalar passa atualmente por um momento de transição referente ao modelo de gestão. O hospital, que era integrado à rede estadual de atenção pública à saúde, a partir de 2009 passou a integrar a rede municipal, de acordo com o pacto de gestão firmado entre a instituição e a prefeitura local.

A enfermagem vem gradualmente se inserindo nessa nova condição, uma vez que atuava de forma semelhante à atenção básica, com atendimento sistemático e de longo prazo às pessoas com DM. Agora, como serviço de atenção especializada, caracteriza-se como uma "unidade ambulatorial de referência, composta por uma equipe multidisciplinar que acompanha os pacientes com DM tipo 1 e 2, prestando atendimento integral a eles e a seus familiares" ${ }^{\prime 11)}$. A escassez de trabalhos em torno do cuidado de enfermagem à saúde na atenção ambulatorial especializada justificou a escolha desse campo para o estudo.

Participaram do estudo 20 homens e mulheres maiores de 18 anos, com DM tipo 1 ou tipo 2, diagnosticado há pelo menos um ano, usuários do ambulatório, tendo realizado pelo menos uma consulta de enfermagem.

A coleta de dados ocorreu com a realização de entrevistas semiestruturadas no período de março a maio de 2010, orientadas por um roteiro que buscou levantar diferentes perspectivas acerca da atenção recebida das enfermeiras no ambulatório. Assim, tentamos apreender como as pessoas com DM vêm sendo atendidas na atenção especializada ambulatorial em relação à humanização do cuidado de enfermagem. $\mathrm{O}$ roteiro foi composto por duas partes: I. Dados de Identificação do Usuário e II. Perspectivas sobre a Humanização do Cuidado às Pessoas com DM, focando o Acolhimento e o Vínculo.

As pessoas com DM que se enquadravam nos critérios de inclusão foram convidadas a participar do estudo após realizarem as consultas ou procedimentos no ambulatório. Diante da aceitação e da disponibilidade de tempo do usuário, a entrevista era realizada em algum consultório do ambulatório, propiciando um ambiente de privacidade, confortável, com boa luminosidade e sem ruídos ou interrupções. Nos casos em que o usuário demonstrou interesse em participar da pesquisa, porém não dispunha de tempo para responder à entrevista, foram agendados data, horário e local de preferência do usuário para o novo encontro. Geralmente o local escolhido era o próprio domicílio do usuário. Nesses casos, foi efetuado contato telefônico na véspera da entrevista para confirmar a disponibilidade do usuário e seu endereço residencial.

Os registros dessas informações foram efetuados através de gravação em aparelho eletrônico com a devida autorização dos usuários entrevistados e posterior transcrição das entrevistas.

A análise de dados ocorreu paralelamente à coleta dos dados. A análise e a interpretação dos dados obtidos nas entrevistas foram orientadas pela proposta de autoras ${ }^{(12)}$ que tiveram como referência Morse \& Field, e que consta de quatro processos genéricos: apreensão, síntese, teorização e recontextualização.

O processo de apreensão envolveu a organização dos dados por meio de identificação, codificação e criação de categorias. A codificação deu-se após leitura e destaque na transcrição das entrevistas, das palavras, frases ou temas relacionados à temática em estudo. As categorias foram compostas pelo conjunto de códigos semelhantes ou expressões com características similares que tinham relação de complementaridade entre os dados.

Durante a fase de síntese, houve a releitura atenta das categorias que sintetizam o conteúdo das falas dos entrevistados, demandando um profundo trabalho intelectual. Na teorização buscou-se desenvolver um esquema teórico, o que implicou um trabalho de especulação, verificação, seleção e descarte. A interpretação foi feita à luz da fundamentação teórica 
utilizada e com a revisão de literatura. Na recontextualização, buscou-se dar significado aos achados, contextualizando a temática da pesquisa.

A inclusão dos sujeitos no estudo obedeceu a Resolução no 196/96 CNS/MS. O projeto foi aprovado em dezembro de 2009 pelo Comitê de Ética da instituição hospitalar e pelo Comitê de Ética em Pesquisas com Seres Humanos da Universidade Federal de Santa Catarina, sob o protocolo número 535. As vinte pessoas com DM incluídas no estudo foram identificadas como U1 até U20, mantendo o sigilo sobre suas identidades, sendo que a vogal $U$ relaciona-se à condição de "usuários" do serviço público de saúde.

\section{RESULTADOS E DISCUSSÃO}

Dentre as 20 pessoas com DM entrevistadas, 17 eram do sexo feminino e três do sexo masculino, havendo, portanto, o predomínio de mulheres. A média de idade foi 62,5 anos e a renda familiar entre dois e quatro salários mínimos, refletindo a condição predominante de aposentados ou pensionistas. Em relação ao estado civil, a maioria se apresentou como casada ou viúva. Na maioria dos casos, o grau de instrução não ultrapassou o ensino fundamental. O tempo de diagnóstico do DM variou de três a 35 anos. Dentre os diagnósticos associados, os mais comuns foram os eventos cardiovasculares e os problemas osteoarticulares - condições comuns se considerarmos a média de idade das pessoas entrevistadas.

A análise e interpretação dos dados permitiram a construção de quatro categorias que sustentam a concepção das pessoas com DM acerca da humanização dos cuidados de enfermagem desenvolvidos no atendimento especializado ambulatorial. Ao explorar como o acolhimento e o vínculo expressam-se na prática assistencial das enfermeiras, emergiu a valorização dos atos de escuta e diálogo, o relacionamento afetivo, a resolutividade e a facilidade de acesso aos serviços de enfermagem, gerando as seguintes categorias: A arte do encontro; Ultrapassando a relação profissional formal; $\mathrm{O}$ compromisso genuíno; e Um breve olhar sobre o acesso.

\section{A. A arte do encontro}

No processo de atenção à saúde, o profissional e o usuário - dois sujeitos dotados de intenções e saberes - ficam submetidos à comunicação e inter-relacionamento. Trata-se de um encontro refletido em arte por envolver criatividade diante da imprevisibilidade da demanda que o profissional atende. Cada encontro abre espaço para o usuário expor suas necessidades, expectativas ou situações. Se cada sujeito é único, também suas necessidades e expectativas serão singulares, o que exige que os profissionais de saúde considerem a diversidade cultural e socioeconômica e a subjetividade de cada um.

A escuta e o diálogo fazem parte da assistência em saúde nos encontros entre as enfermeiras e as pessoas com DM que integraram o estudo. A escuta permite que os encontros evoluam para além dos aspectos clínicos da condição crônica de saúde, envolvendo a subjetividade, expressa em palavras e sentimentos. Os usuários percebem que são ouvidos com atenção e que as suas preocupações são consideradas pelas enfermeiras, havendo abertura para a conversa, quando desfrutam de espaço para colocar suas dúvidas e angústias, como mostram os relatos a seguir:

Não sei se estou certa ou se estou errada, mas é até um certo desabafo (a consulta de enfermagem). Ela escuta com atenção, conversa, orienta. A enfermeira é muito boa. (U10)

[...] problemas pessoais eu sempre converso com ela, ela sempre tem aquele carinho, ela escuta. Por isso, eu digo, ela é mais que uma enfermeira. Ela escuta, é aquela pessoa que escuta. Então isso dá abertura para gente, e é importante para tu te sentires segura. (U14)

Com o estabelecimento de diálogo entre trabalhador da saúde e usuários, as soluções para os problemas de saúde são encontradas na parceria, no compartilhamento de ideias, pois, muitas vezes, o desabafo pode proporcionar resoluções para as dificuldades presentes. A escuta sensível e o diálogo aberto parecem colocar as enfermeiras num papel diferente, especial, não sendo vistas somente como profissionais da saúde, mas como alguém mais próximo, como pessoas a quem podem confiar segredos. A prática cotidiana da escuta e do diálogo suscita, como consequência, o relacionamento afetivo entre profissional e usuário, tema que se encontra explorado mais profundamente na próxima categoria.

A abertura para discussão de situações pessoais e específicas de saúde envolve o compartilhamento de ideias e saberes entre profissional e usuário. O processo de cuidar, no sentido da relação entre dois seres humanos, tem duas vias: o de um ser humano dotado de preparo técnico-científico e humanístico e disponível para o cuidado efetivo e de outro ser que, necessitando de ajuda de um profissional, busca assistência em estado físico e emocional fragilizado(13). Desse modo, é promovido o encontro entre o usuário e o trabalhador de saúde, em que se fomenta um espaço para o estabelecimento de relações, compartilhamentos de experiências e criação de vínculo ${ }^{(9)}$.

O tempo de duração das consultas de enfermagem, de 20 a 45 minutos, dependendo do caso, também é ressaltado, revelando que, quando não há pressa por parte do profissional de saúde, o usuário sente-se mais à vontade para colocar suas dúvidas, angústias, alegrias e conquistas, tanto sobre o cuidado com a condição crônica de saúde como sobre questões pessoais. Para o exercício de um bom diálogo, faz-se necessário uma escuta atenta, buscando detalhes que podem estar ocultos nas falas, além do acolhimento e o vínculo, que são atributos da assistência integral ${ }^{(14)}$.

Os usuários dos serviços de saúde têm um desejo profundo de ser compreendidos em suas necessidades, tal compreensão é um passo fundamental do cuidar e requer o compromisso do profissional. É essencial que haja a devida disponibilidade para que isso ocorra, o que demanda certa condição corporal e mental. É importante, notadamente a partir da perspectiva do profissional, a abertura para a verdadeira efetivação do cuidado em sua plenitude, pois isso certamente contribuirá para a humanização da assistência ${ }^{(13)}$. 
O encontro dos usuários com as enfermeiras é valorizado por sua especificidade, pela percepção de que são únicos naquele momento, que não há somente uma receita a ser seguida, mas que as enfermeiras têm uma comunicação e aproximação que permitem à pessoa sentir-se diferenciada. A arte desse encontro expressa-se através da sensibilidade das enfermeiras em ouvir com atenção, construir um diálogo afetuoso e indicar caminhos que possam antecipar soluções de problemas em relação à saúde.

\section{B. Ultrapassando a relação profissional formal}

Faz parte do acolhimento e estabelecimento de vínculo propiciar ao usuário a liberdade de expressão durante a atenção em saúde. Observou-se que no relacionamento entre as enfermeiras e as pessoas com DM há espaço para o compartilhamento de experiências e esclarecimento de dúvidas, havendo interesse constante na verificação da compreensão que o usuário teve sobre o que foi orientado, sendo estes importantes aspectos pautados na estrutura da $\mathrm{PNH}^{(9)}$.

Ao falarem das enfermeiras, os usuários identificam-nas sempre pelo nome, fato que demonstra uma referência de profissional bem estabelecida e a existência de um relacionamento simétrico, enquanto que a maioria dos outros profissionais são identificados por suas especialidades profissionais ou função, como "o cardiologista", "o vascular", "a psicóloga", "a atendente".

Os usuários destacaram a intimidade e a liberdade que sentem perante as enfermeiras, evidenciando a fácil comunicação e demonstrando contentamento pela atenção em saúde recebida:

É muito bom a gente ir lá porque ela explica tanta coisa, a gente sai de lá bem orientado, ela é muito querida mesmo, a gente se sente à vontade com ela. (U16)

Houve ênfase nos relatos dos usuários sobre o vínculo estabelecido com as profissionais de enfermagem, evidenciando que a relação com as enfermeiras vai além do aspecto profissional. Ocorre acolhida afetiva, mantendo-se um bom relacionamento, que é descrito por muitos como "relação de amizade ou relação familiar":

É com certeza mais que uma profissional, é uma amiga! (U14)

É uma afinidade tão grande, tão grande! Porque, eu não conhecia ela e a gente pegou aquela confiança, dá a impressão que ela é nossa mãe! (U6)

Tal relacionamento nos faz refletir sobre as facilidades e dificuldades na manutenção do acompanhamento em saúde e relacionamento mais denso entre profissional e usuário no cenário da atenção especializada, o qual, segundo o regulamento do sistema de saúde brasileiro, refere-se a um nível de atenção voltado a atender apenas "casos que demandam assistência de maior complexidade" ${ }^{\prime(15)}$. Caberia, portanto, ao nível de atenção básica, o estabelecimento de acolhimento e vínculo com os usuários para efetivar o acompanhamento em saúde. No entanto, a PNH traz a atenção especializada em unidade ambulatorial como sendo um serviço com a função de acompanhar a saúde dos usuários, prestando-lhes atendimento integral ${ }^{(9)}$.

Alguns fatores devem ser considerados para o estabelecimento da relação horizontal profissional e usuário, fugindo à relação hierárquica biomédica: é importante haver empatia e afinidade, fortalecidas com acolhimento, vínculo, confiança, tempo disponível para oferecer tal atenção e retornos frequentes para o acompanhamento em saúde.

Um fator significativo para o exercício da assistência acoIhedora e o estabelecimento do vínculo é a característica pessoal do profissional. No caso das enfermeiras observadas, percebeu-se o perfil acolhedor, compromisso e defesa dos interesses dos usuários. Estes, por sua vez, descrevem as profissionais de acordo com o relacionamento que mantêm:

Sempre ela atende muito bem as pessoas. Para mim ela é muito educada, prestativa. Ah, é cem porcento! É sempre contente, sempre calma, sempre tranquila, sabe, fazendo o trabalho dela mesma. Problema todo mundo tem, mas se ela tem, ela deixa de lado assim, esquece tudo ali no trabaIho dela e vive para gente, assim, com muito carinho. [...] $A h$, eu gostei dela e foi amor à primeira vista (risos). Desde a primeira vez que eu consultei com ela, quando não tinha vaga para a outra enfermeira, eu comecei a consultar com ela, aí gostei demais dela, adorei o jeitinho dela, a fala dela, como ela trata a gente com respeito. Então é isso, compreende quando a gente está mais amargurada e quando está menos, né? Que às vezes é assim. (U20)

Esta situação mostra o quanto a humanização da assistência ainda não é uma realidade global na atenção à saúde, ressaltando que as atitudes pontuais e específicas dessas profissionais são ressaltadas mais como uma característica pessoal do que profissional.

Ainda em relação às características das profissionais e suas abordagens, a relação afetiva que permite o contato físico como forma de carinho foi um elemento favorável. Ao aparecer em diversas falas, o abraço, como uma importante ação na relação com o profissional, percebemos que a demonstração de afeto ajuda a manter o relacionamento informal. $\mathrm{O}$ relacionamento físico acontece naturalmente quando há empatia e afinidade entre dois sujeitos. Muitas vezes é terapêutico por ser acolhedor e desencadear alívio e bem estar às angústias do usuário.

Ela me cativa muito, me cativa bastante. E já teve momentos aí que no corredor ela ia passando e veio e me abraçou, conversou comigo. E a gente fica muito feliz com isso, né? (U13)

O gesto do abraço apresenta-se como forma expressiva de comunicação e afeto no relacionamento humano. $O$ fortalecimento de sentimentos de solidariedade, respeito e compreensão, no contexto da humanização, é considerado fundamental para o despertar da sensibilidade humana de uns para com os outros. 
O abraço emerge do próprio ato de existir no mundo com os outros, já que não existimos apenas, coexistimos e convivemos com as realidades mais adversas. $\mathrm{O}$ abraço revela a capacidade de o ser humano de se emocionar, envolver-se e comprometerse afetivamente - ações indispensáveis para a conquista de um novo espaço no contexto interdisciplinar da saúde ${ }^{(16)}$.

O bom relacionamento cria um elo entre profissional e usuário, estimula a assiduidade nas consultas, tornando o acompanhamento em saúde mais efetivo. Por outro lado, pode gerar dificuldades no estabelecimento de limites entre a atenção do profissional e as relações sociais pessoais. Novamente destacamos que o modelo de saúde hegemônico sempre enfatizou uma hierarquia entre profissionais e usuários, em que o profissional é aquele que sabe, que determina e que está preocupado com a resolução da alteração do corpo doente. Assim, pode haver dificuldades para os usuários entenderem que uma relação afetuosa também é profissional, não mudando o papel do enfermeiro, mas promovendo uma relação mais harmoniosa e próxima que favorece o cuidado e a adesão ao tratamento. $\mathrm{O}$ estabelecimento de acolhimento e vínculo permite que os profissionais de saúde supram necessidades, intervenham, aconselhem e promovam suporte psicológico aos usuários que buscam a assistência em saúde, desenvolvendo ações voltadas para o alívio das ansiedades e necessidades ${ }^{(17)}$.

Assim, o relacionamento horizontalizado percebido na assistência de enfermagem às pessoas com DM expressa-se através de liberdade de expressão dos usuários, compartilhamento de experiências, relação amigável e de confiança, empatia e afinidade, perfil acolhedor do profissional, afeto, contato físico e retornos frequentes, fomentando o acompanhamento em saúde.

\section{O compromisso genuíno}

$\mathrm{Na}$ atenção em saúde dispensada pelas enfermeiras aos usuários, o compromisso com as pessoas com DM é percebido através do interesse e empenho na busca por resolutividade diante das solicitações e situações apresentadas e cuidados realizados baseados na abordagem integral aos sujeitos. A ajuda recebida é observada como um fator importante de satisfação por gerar resolutividade na assistência.

O papel da enfermeira vai além da conversa no consultório, como já mencionado, envolvendo atos de ajuda e empenho para a resolução de problemas relativos ao estado de saúde e a situações pessoais. As "ajudas" citadas pelos usuários referem-se a diversas situações do dia-a-dia, quando os usuários buscam nas enfermeiras orientações ou encaminhamentos, o atendimento de enfermagem sem marcação prévia, a obtenção de insumos como seringas e insulina, se disponíveis; a busca por conselhos sobre sua condição de saúde ao surgirem dificuldades nos cuidados, tratamento e/ou controle do DM, o que, ao mesmo tempo, evidencia a valorização dos saberes das profissionais, reconhecendo sua capacidade de encontrar soluções para os problemas.

Na perspectiva dos usuários, o aconselhamento é um tipo de ajuda realizado pela enfermeira que é bastante valorizado, principalmente quando gera conhecimento, autonomia, estímulo e motivação. $\mathrm{O}$ aconselhamento é entendido no sentido de indicar um caminho e facilitar o enfrentamento da condição de saúde ou situações do dia-a-dia:

A enfermeira mais é os conselhos, aquele ânimo que ela dá para gente, ela motiva muito, muito a gente, porque eu era uma pessoa que vivia muito em casa, meu marido era doente... Ela me estimulou até a tomar a insulina. (U6)

[...] pela dedicação dela, a enfermeira é uma excelente pessoa. Ela foi me encaminhando, foi me ajudando, foi me fazendo umas perguntas e a hora que eu precisava de algum exame ou alguma coisa, ela sempre estava ali para me ajudar. E conversava comigo, aquilo ali foi uma excelente coisa. (U15)

Considerar as preocupações dos usuários e dar respostas para seus problemas ou queixas - tanto relacionados à situação de saúde como os de ordem pessoal - promove a prática da atenção em saúde acolhedora, integral e que expressa compromisso com os sujeitos. Além disso, frente às atitudes de empenho e valorização dos sujeitos, as profissionais passam a ser uma importante referência para o usuário quando este necessita de auxílio, fortalecendo o vínculo profissional e usuário.

O conceito de profissional de referência é um instrumento importante para a construção da clínica ampliada - diretriz da PNH que propõe mudanças nos modos de fazer a atenção em saúde ${ }^{(9)}$, culminando na humanização da assistência. Todos os profissionais devem refletir e conscientizar-se de que a atenção em saúde deve ser totalizadora, humanizada, contextualizada, integral e principalmente deve ser considerada uma prioridade na prática ${ }^{(18)}$.

Observou-se que a resolução das demandas dos usuários é possível quando há interesse genuíno das enfermeiras pela saúde e bem-estar dos usuários. Tal interesse reflete a corresponsabilidade pela saúde, pelos cuidados e tratamentos e ressalta o compromisso que as enfermeiras assumem de acordo com a lei do exercício profissional em respeito às pessoas com DM. Os usuários expressam o reconhecimento da dedicação das profissionais de enfermagem, conforme indica a fala abaixo:

Ela tem interesse em cuidar dos pacientes dela. Ela participa, né? Eu gosto dela, ela tem uma grande preocupação. (U10)

O compromisso de fornecer aos usuários as melhores condições para um controle efetivo de sua condição e um viver mais saudável parece estar numa linha tênue entre um cuidado integral e uma assistência paternalista, que pode gerar dependência ao profissional, restringindo, de certa forma, a liberdade do paciente. Neste sentido, refletimos sobre a polaridade representada pelo paternalismo e a autonomia diante da relação médico-paciente, trazendo a possibilidade de uma visão que integre ambos os aspectos, fundamentando-se na dignidade do ser humano e no saber médico ${ }^{(19)}$. A humanização da saúde, proposta pelo Ministério da Saúde na $\mathrm{PNH}^{(9)}$, incentiva um movimento pautado na ética, em que todos 
devem ser tratados com igualdade, e estimula os profissionais da saúde a terem a visão do usuário como um sujeito autônomo, protagonista e corresponsável pela sua saúde.

Percebemos, assim, que o modelo de atenção do processo de trabalho das enfermeiras nega a visão exclusivamente biomédica, na qual a doença e os sintomas são objetos centrais de atenção, considerando predominantemente os aspectos orgânicos. As práticas de cuidados ocorrem no sentido da ampliação da clínica, pois implicam valorização da subjetividade, compromisso com o usuário e seu contexto, reconhecimento dos limites dos saberes do usuário, estabelecimento de relação de coprodução do cuidado durante o encontro profissional e usuário e ainda objetiva produção de saúde procurando fomentar a autonomia dos usuários, conforme a proposta da $\mathrm{PNH}^{(9)}$.

Favorecer a integralidade implica fazer com que a atenção em saúde seja ampla e desfragmentada, que os profissionais relacionem-se com os sujeitos como seres humanos e não como objetos. Cumprir esse princípio garante a qualidade e a resolutividade da atenção à saúde, dotando as diversas fases da atenção, de acolhimento e cuidado ${ }^{(18)}$.

Percebemos que as enfermeiras do ambulatório prezam pelo compromisso com a atenção integral e humanizada em saúde às pessoas com DM, expresso nos aconselhamentos, encaminhamentos, “ajudas" diversas e principalmente pelo empenho e dedicação cotidiana para a resolutividade das situações demandadas pelos usuários.

\section{A informalidade do acesso}

A facilidade de acesso é um aspecto valorizado pelos usuários em relação à atenção em saúde dispensada pelas enfermeiras do local de estudo, conforme indicado nas falas:

Eu tenho a felicidade de telefonar, às vezes ela marca, ou eu vou lá no ambulatório e marco lá. (U6)

Lá onde marca a consulta, eu vou lá. Se eles marcarem, eu marco para aquele dia porque daí meu prontuário já vem para ali. Se lá na frente, lá onde marcam as consultas, eles disserem que não tem agenda dela ou qualquer coisa aí eu venho direto ali, daí ela (a enfermeira) manda pegar meu prontuário, ela dá um jeito sempre. (U11)

O acesso à consulta de enfermagem acontece de duas formas: formalmente, através do sistema de marcação de consultas ou pelo encaminhamento de outros profissionais que compõem a equipe multiprofissional de atenção à saúde do ambulatório; ou informalmente, bastando ir até o ambulatório ou fazer contato por telefone e solicitar atendimento de enfermagem. Essa última forma é extremamente valorizada e considerada uma assistência diferenciada, pois isso não ocorre em outros serviços, evidenciando o respeito e a consideração que as enfermeiras têm pelos usuários que atendem. Isto é possível pela autonomia e organização, na dinâmica de atendimento que as enfermeiras assumem no ambulatório, com vistas a terem sempre espaço em suas agendas para esses atendimentos eventuais.
Muitas vezes, esse acesso informal ocorre para solucionar uma dúvida do usuário quanto aos seus cuidados e tratamentos do DM ou para obter informações acerca de outros profissionais da saúde. Assim, a disponibilidade das enfermeiras em escutar, considerar as preocupações ou queixas e conversar por alguns minutos ou até mesmo o atendimento via telefone torna a atenção eficiente e satisfatória na perspectiva do usuário.

Se considerarmos as políticas de saúde, podemos pensar essas atitudes tomadas pelas enfermeiras como ações em saúde pautadas no acolhimento e na solidariedade diante dos vínculos estabelecidos e que vão ao encontro dos valores estabelecidos pela $\mathrm{PNH}^{(9)}$. Assim, gera-se resolutividade e consequente satisfação dos usuários, que podem contar com o atendimento sem barreiras, como as longas filas de espera, quando o problema a ser resolvido é pontual e exige pouco tempo de atenção do profissional.

Com relação à organização do serviço e da instituição para esse acesso informal, há implicações que não serão aprofundadas aqui, uma vez que a proposta do estudo foi a avaliação do ponto de vista do usuário. No entanto, vale ressaltar que esse tipo de situação gera certo contraste entre a literatura e a prática, remetendo-nos à reflexão acerca da limitação do atendimento especializado existente na rede do SUS.

Médicos e enfermeiras participantes de um estudo em grandes centros urbanos avaliaram que os problemas decorrentes das listas de espera, impedindo o acesso adequado ao cuidado especializado e hospitalar, é o principal entrave da integração da rede de serviços de saúde. O autor do estudo sugere a realização de pesquisas centradas em avaliações da cobertura da média complexidade e integração da rede na perspectiva de trazer novas contribuições e elementos ao debate $^{(20)}$.

Um dilema que aflige as enfermeiras é de atender bem a poucos usuários ou a muitos, porém com menor qualidade na atenção devido ao alto fluxo, sem fomento ao vínculo. Esta é uma situação que merece estudos aprofundados, visto que envolve questões éticas, pois a escolha de uma ou outra situação gera consequências aos usuários, contrapondo-se à própria Constituição e aos princípios do SUS.

As quatro categorias apresentadas expõem a prática da atenção humanizada, em que o acolhimento e o vínculo expressam-se de maneira diferenciada. A política institucional de humanização e as atitudes adotadas pelas enfermeiras em consonância com os conceitos abordados e com a PNH estão evidenciadas nos mais variados aspectos que envolvem o cuidado de enfermagem às pessoas com DM nesse serviço especializado.

Algumas características do serviço de saúde avaliado são elementos essenciais e que merecem ser destacados, pois integram o contexto onde as ações de enfermagem ocorrem e propiciam tal atendimento diferenciado:

$\checkmark$ há autonomia das enfermeiras para o estabelecimento do número de atendimentos por dia em suas agendas, deixando espaços para atendimentos não previstos e reservando o tempo que julgam necessário e adequado para cada usuário na consulta de enfermagem; 
$\checkmark$ as enfermeiras e a técnica de enfermagem atuam neste local há longo tempo, reconhecendo e sendo reconhecidas pelos usuários e demais profissionais, com uma história de compromisso e cuidado humanizado;

$\checkmark$ o processo de transição do modelo de atenção básica para o especializado vem sendo construído com base em discussões, com possibilidade de manter o atendimento periódico e as consultas informais;

$\checkmark \quad$ a atuação multiprofissional no ambulatório gera a possibilidade de articulação entre os especialistas que atuam no setor, favorecendo uma atenção mais integral e resolutiva.

\section{CONSIDERAÇÕES FINAIS}

Neste estudo, identificamos que ocorre o cuidado de enfermagem humanizado segundo o julgamento das pessoas com DM entrevistadas e também quando comparados os nossos achados com a PNH e autores supracitados. No entanto, as condições distintas que existem no serviço avaliado podem ser consideradas como privilegiadas, não representando a realidade da maioria dos serviços de média complexidade integrados ao SUS.

O acolhimento é reconhecido como parte dos cuidados de enfermagem e há vínculo estabelecido com as enfermeiras, sendo que estes aspectos expressam-se na atenção em saúde recebida. Os usuários relacionam a ocorrência da atenção humanizada com as atitudes das profissionais enfermeiras que, entre outros aspectos, destacam-se pela escuta sensível, acoIhimento dialogado, resolutividade, compartilhamento de saberes e aconselhamento presentes nos encontros, formalizando a valorização da dimensão subjetiva e social dos usuários.

$\mathrm{O}$ interesse, o empenho e a resolutividade ocorrem dentro da abordagem integral que se dá mesclando a objetividade da clínica normatizada por princípios tecnocientíficos com a subjetividade inerente aos sujeitos e suas situações específicas de saúde.

Destacou-se ainda a interação que privilegia a liberdade de expressão dos usuários, intimidade, amizade dentro da relação afetiva, em que as características pessoais das profissionais refletem-se em suas abordagens, garantindo respeito mútuo e ética no cuidado humanizado.

Por se tratar de uma pesquisa avaliativa, esperávamos que emergissem nos relatos dos usuários sugestões de mudanças para a melhoria da prática assistencial no ambiente ambulatorial. Com relação à satisfação e organização dos serviços das enfermeiras, houve elogios de forma universal, atestando o exercício do cuidado de enfermagem humanizado.

Neste sentido, a principal contribuição que este estudo avaliativo traz é o que os usuários consideram como importantes numa atenção que é de qualidade, tem resolutividade e promove sua saúde. Por outro lado, também nos mostra que para que a atenção em enfermagem tome como referência conceitos como acolhimento e vínculo, há necessidade de discutir a autonomia do profissional, fixação do profissional em um mesmo serviço e relacionamento contínuo com os usuários. Mesmo que possa ser considerada ainda como uma utopia em termos do sistema de saúde brasileiro, é um ideal a ser perseguido.

Apesar de vivenciarmos importantes avanços teórico-filosóficos, legais e nas práticas de atenção à saúde no cenário brasileiro, a humanização intrínseca à integralidade da assistência como princípio constitucional do SUS ainda é um grande desafio aos modelos de atenção e de gestão vigentes. Conhecimento acerca desses e de outros tópicos contribuem para o planejamento de estratégias de assistência humanizada e para o aprimoramento de modelos de avaliação qualitativa nos serviços públicos de saúde.

\section{REFERÊNCIAS}

1. Ministério da Saúde. Diabetes. Dados Estatísticos 2007. [monografia na internet]. [acesso em 27 out 2010]. Disponível em: < http://portal.saude.gov.br/portal/saude/visualizar_texto.cfm?idtxt $=29793 \&$ janela $=1>$

2. Ministério da Saúde. Diabetes Mellitus, Cadernos de Atenção Básica. [monografia na internet]. 2006 [acesso em 15 set 2010]. Disponível em: <http://bvsms.saude. gov.br/bvs/publicacoes/diabetes_mellitus.pdf $>$

3. Ministério da Saúde (Brasil). Portaria n. ${ }^{\circ} 2.583$, de 10 de outubro de 2007. Define elenco de medicamentos e insumos disponibilizados pelo Sistema Único de Saúde, nos termos da Lei $\mathrm{n}^{\circ} 11.347$, de 2006, aos usuários portadores de diabetes mellitus. [portaria na internet] Diário Oficial da União 15 out 2007 [acesso em 10 ago 2009 ago]. Disponível em: < http://portal.saude.gov.br/portal/ arquivos/pdf/portaria_2\%20583_lei_diabetes.pdf >

4. Brasil. Lei n. ${ }^{\circ} 11.347$, de 27 setembro de 2006. Dispõe sobre a distribuição gratuita de medicamentos e materiais necessários à sua aplicação e à monitoração da glicemia capilar aos portadores de diabetes inscritos em programas de educação para diabéticos. [legislação na internet] Diário Oficial da União 29 set 2006. [acesso em 10 ago 2009]. Disponível em: < http://www.planalto.gov.br/ccivil_03/_Ato2004-2006/2006/Lei/L11347.htm >

5. Rodrigues TC, Pecis M, Canani LH, Schreiner, L, Kramer CK, Biavatti $\mathrm{K}$ et al . Caracterização de pacientes com diabetes mellitus tipo 1 do sul do Brasil: complicações crônicas e fatores associados. Rev Assoc Med Bras [periódico na internet]. 2010 [acesso em 28 set 2010];56(1):67-73 Disponível em: <http://www.scielo.br/scielo.php?script =sci arttext\&pid $=$ S0104-42302010000100019\&Ing = pt\&nrm $=\mathrm{iso}>$

6. Gimenes HT, Zanetti ML, Haas VJ. Fatores relacionados à adesão do paciente diabético à terapêutica medicamentosa. Rev latino-Am Enferm [periódico na internet]. 2009 [acesso em 27 out 2010];17(1) Disponível em: <http:// www.scielo.br/pdf/rlae/v17n1/pt_08.pdf >

7. Uchimura KY, Bosi MLM. Qualidade e Subjetividade na Avaliação de Programas e Serviços em Saúde. Cad Saúde Pública [periódico na internet]. 2002 [acesso em 3 ago 
2009];18(6)1561-9. Disponível em: < <ttp://www.scielo. br/pdf/csp/v18n6/13251.pdf>

8. Trentini M. Pesquisa Avaliativa. In: Trentini M, Corradi EM, organizadoras. Avaliação: subsídios teórico-práticos para a gestão em saúde. São Paulo: Ícone Editora; 2006.

9. Ministério da Saúde, Núcleo Técnico da Política Nacional de Humanização. Política Nacional de Humanização - HumanizaSUS. Documento Base para Gestores e TrabaIhadores do SUS. [monografia na internet] 3. ed. Brasília: Ministério da Saúde; 2008. [acesso em 1 ago 2009]. Disponível em: < http://bvsms.saude.gov.br/bvs/publicacoes/ documento_base.pdf $>$

10. Marques IR, Souza AR. Tecnologia e humanização em ambientes intensivos. Rev Bras Enferm 2010;63(1):141-4.

11. Ministério da Saúde, Núcleo Técnico da Política Nacional de Humanização. Política Nacional de Humanização - HumanizaSUS. Documento Base para Gestores e Trabalhadores do SUS. [monografia na internet] 2. ed. Brasília: Ministério da Saúde; 2006. (Série B Textos Básicos de Saúde) [acesso em 1 ago 2009]. Disponível em: <http://bvsms. saude.gov.br/bvs/publicacoes/documento_base.pdf $>$

12. Trentini M, Paim L. Pesquisa Convergente Assistencial. um desenho que une o fazer e o pensar na prática assistencial em Saúde-Enfermagem. 2. ed. Florianópolis: Insular; 2004.

13. Hoga LAK. A dimensão subjetiva do profissional na humanização da assistência à saúde: uma reflexão. Rev Esc Enferm USP 2004;38(1):13-20.

14. Urbano GB. Integralidade na prática assistencial da equipe de enfermagem: a relação da escuta na interação usuário e profissional no município de Paranavaí - PR. Rio de Janeiro. Dissertação [Mestrado em Saúde Coletiva]- Universidade do Estado do Rio de Janeiro. Instituto de Medicina Social; 2009.

15. Ministério da Saúde (Brasil). Portaria $\mathrm{n}^{\circ}$. 2.048, de 3 de setembro de 2009. Aprova o regulamento do Sistema Único de Saúde (SUS). Seção II Da assistência à saúde. Subseção III Dos portadores de hipertensão arterial e diabetes mellitus. [portaria na internet] Diário Oficial da União 3 set 2009. [acesso em 3 nov 2010]. Disponível em: < http://bvsms.saude.gov.br/bvs/saudelegis/gm/2009/ prt2048_03_09_2009.html>

16. Backes DS, Lunardi Filho WD, Lunardi VL. A construção de um processo interdisciplinar de humanização à luz de Freire. Texto \& Contexto Enferm [periódico na internet]. 2005 [aceso em 22 ago 2010];14(3):427-34 Disponível em: <http://www.scielo.br/scielo.php?script = sci_arttext\&pid $=$ S0104-07072005000300015\&lng =en >

17. Gomes ALC, Sá LD. As concepções de vínculo e a relação com o controle da tuberculose. Rev Esc Enferm USP 2009;43(2):365-72.

18. Fontoura RT, Mayer CN. Uma breve reflexão sobre a integralidade. Rev Bras Enferm 2006;59(4):532-7.

19. Ventura-Juncá P. La relación médico-paciente: ¿Autonomia o Beneficencia? Bioetica y Derecho. Bol Cient Asoc Chil Segur 2001;62-7.

20. Almeida PF, Giovanella L; Mendonça MHM, Escorel S. Desafios à coordenação dos cuidados em saúde: estratégias de integração entre níveis assistenciais em grandes centros urbanos. Cad Saúde Pública 2010;26 (2):286-298. 